\title{
Location in a vertically differentiated industry*
}

\author{
Emanuele Bacchiega $^{\dagger} \quad$ Antonio Minniti ${ }^{\ddagger}$
}

September 2005

\begin{abstract}
We analyze a two-stage game in a vertically differentiated duopoly with two regions which can differ for the willingness to pay of their consumers or for the market size; firms sequentially choose to settle in one region and then simultaneously compete in prices, selling their products both on the local market and on the foreigner one by exporting them at a fixed cost. We study how strategic interaction influences firms' location choices and we show that the decision whether to agglomerate or not crucially depends on the extent of regions' asymmetries, but, counter intuitively, there are parametric regions in which the model predicts that the leader (the first firm choosing location) settles either in the poorer or in the smaller region, leaving the other one to the follower. Welfare analysis completes the paper.
\end{abstract}

Keywords: Regions, Vertical Differentiation, Oligopoly.

JEL Classification: D43, L13, R12.

\section{Introduction}

This paper studies the geographical location choices of firms selling vertically differentiated variants of a commodity. The study of the distribution of activities among locations has been widely investigated by economic theory. Industrial Organization has mostly dealt with horizontal product differentiation, departing from the pioneering work of Hotelling (1929). The flexibility of the linear

${ }^{*}$ The authors wish to thank professor R. Amir, professor C. d'Aspremont, professor V. Denicolò, A. Dominioni, professor Jean J. Gabszewicz, professor P. Garella, professor S. Weber and the audience at the EARIE 2005 conference in Porto for helpful discussions and suggestions. A previous version of article originally formed a chapter of the $\mathrm{PhD}$ Thesis of $\mathrm{A}$. Minniti, Università degli Studi di Bologna, 2005. A. Minniti acknowledges the financial support of the Belgian research programmes "Poles d'Attraction inter-universitaires" PAI P5/21. The usual disclaimer applies.

${ }^{\dagger}$ Dipartimento di Scienze Economiche, Università degli Studi di Bologna, Strada Maggiore 45, 40125 Bologna Italy; tel: +390512092603, fax: +390512092664, e-mail: bacchieg@spbo.unibo.it

$\ddagger$ CORE-IRES, Université Catholique de Louvain, 34, voie du Roman Pays, 1348 Louvainla-Neuve Belgium; tel: +3210473987, e-mail: minniti@core.ucl.ac.be 
(or circular) city model has allowed scholars to deeply exploit the parallelism between geographic space and product space. An important result of this literature is that if firms compete in prices they tend to locate far from each other (D'Aspremont et al. (1979), D’Aspremont et al. (1983), Hamilton et al. (1989), Kats (1995)); the basic intuition behind the result of maximum differentiation is that, once firms locate close to one another, price competition becomes intense and decreases profits.

However, Anderson and Neven (1991) show that setting quantity rather than price as the strategic variable may contribute to agglomeration.

Recently, Pal (1998) suggests that whether firms agglomerate or not depends not only on market structure, but also on the actual shape of the market. In fact, if firms choose sequentially locations and quantities, different location patterns emerge: in a circular city, firms locate equidistant from each other and in a linear city, firms agglomerate at the center.

In addition, IO literature has outlined the existence of some forces that may make firms prefer to locate near each other. In de Palma et al. (1985) large enough heterogeneity in consumers' tastes relaxes price competition and may lead to minimum differentiation. Collusion is another mechanism that, by keeping prices high, may contribute to agglomeration (Jehiel (1992) and Friedman and Thisse (1993)). ${ }^{1}$

There is also a large body of literature in International Trade that studies the same issue and investigates the factors that influence the geographic distribution of firms. New Economic Geography (NEG) models (see Krugman (1991), Fujita et al. (1999) for instance), assume that the set of geographic locations among which agents can choose is discrete; in addition, most of this literature relies on models of monopolistic competition, usually in the Dixit-Stiglitz formalization: firms are small relative to the size of the market, so that strategic interdependence among firms is ruled out. ${ }^{2}$

The aim of this paper is to study the location choices of firms operating in a vertically differentiated industry; in particular, we emphasize the role of strategic interaction in determining the equilibrium geographic distribution of firms. Our objective is to study firms' incentives to agglomerate when the possible locations

\footnotetext{
${ }^{1}$ Other explanations on the existence of agglomeration are based on the fact that consumers are not perfectly informed about prices or product characteristics and are often characterized by tastes that are not uniformly distributed.

${ }^{2}$ The assumption is that there is a continuum of firms, so that "the effect of the price of any one good on the demand of any other will be negligible. The result is that each firm can ignore the effect of its actions on other firms' behavior, eliminating the indeterminacies of oligopoly" (Krugman (1980)).
} 
differ because of consumers characteristics: willingness to pay and market size. Consistently, we abstract from technological asymmetries between firms.

The analysis is based on a model in which two firms, each one producing one (out of two) variant of a vertically differentiated good, sequentially choose to settle in one (out of two) region and then simultaneously compete in prices, selling their products both on their local market and exporting them, at a fixed cost to the foreigner one. Our approach differs from the linear city one, because we restrict the set of possible geographical locations to a discrete one: indeed firms, when deciding where to settle physically, are confronted, at least at a first moment, with a discrete set of countries, regions or cities, and we consider as exogenous the vertical quality levels of varieties. On the other hand, differently from the NEG approach, we adopt a partial equilibrium approach and we explicitly model strategic interaction between firms. The structure of our model is formally related to the contributions by Schmitt (1995) and Andaluz (2000) who study the issue of product choice in oligopoly where two markets are separated by transportation costs. These authors, however, do not deal with firms' geographical location choices.

We study the sequential location choices of firms as a function of the parameters defining the asymmetries between locations. Our results show, as it would have been expected, that the decision whether to agglomerate or not crucially depends on the extent of such asymmetries, but, interestingly, there are parametric configurations for which the model predicts that the leader (the first firm choosing location) settles either in the poorer or in the smaller region, leaving the other one to the follower. Welfare analysis completes the study.

The remainder of the paper is organized as follows. In section 2 we present the model. section 3 is devoted to equilibrium analysis while in section 4 we study the welfare properties of the model. In section 5 we briefly discuss the results proposing some interpretations concerning firms (re)location and the role of public intervention, finally section 6 provides a short conclusion.

\section{The model}

Consider an oligopolistic industry in which two geographic locations are possible and label these two regions $A$ and $B$. Moreover, assume that two firms can produce one of the two variants ( $h$ for high-quality and $l$ for low-quality) of a vertically differentiated good each. Firms first sequentially and costlessly settle in one of the two regions and then simultaneously compete in prices to maximize 
profits. Since we do not deal with quality choice -the variant firms produce is a datum of the model-, the goods' quality levels identify firms from the beginning of the game.

Regions can differ with two respects, namely $(a)$ the mass of consumers and (b) the willingness to pay for quality: we will discuss these two issues separately, keeping alternatively one variable constant across regions and letting the other vary.

(a) When regions have different consumer masses, we normalize the mass of consumers in region $B$ to 1 and we assume that it is equal to $\alpha \geqslant 1$ in region $A$. In this case the consumers' appreciation for quality is uniformly distributed over the interval $[0,1]$ in both regions.

(b) Similarly, when regions differ because of the consumers' willingness to pay for quality, we assume that the parameter $\theta$, which measures the extent of quality appreciation among consumers, is uniformly distributed on the support $[0,1]$ in region $B$ and on the support $[0, \bar{\theta}]$ in region $A$, with $\bar{\theta} \geqslant 1$. Consumers' masses are then normalized to 1 both in $A$ and in $B$.

Notice that both $\alpha$ and $\bar{\theta}$ simultaneously represent the absolute size of region $A$ 's consumers' mass or willingness to pay and a relative measure of asymmetry between locations.

In both cases we assume that consumers are immobile, each of them buys at most one unit of the good, either high- or low-quality, and that goods can be shipped across regions at a constant transportation cost, borne by consumers, equal to $t$. Moreover, markets are segmented: arbitrage between regions is ruled out, so that firms can fully exploit their price-setting power.

Consumers in both regions are characterized by a utility function à la Mussa and Rosen (1978). Assume that good $i(i \in\{h, l\})$ is produced in region $j$ $(j \in\{A, B\})$, then, the utility of consumer $\theta$ is:

$u()=.\left\{\begin{array}{rc}\theta k_{i}-p_{i}^{j} & \text { if he buys one unit of variant } i \text { residing in region } j, \\ \theta k_{i}-p_{i}^{z}-t & \text { if he buys one unit of good } i \text { residing in region } z \neq j, z \in\{A, B\} \\ 0 & \text { if he does not buy any product. }\end{array}\right.$

The parameter $k_{i}, i \in\{h, l\}$, represents the quality level of good $i$, with $k_{h}>k_{l}$. $p_{i}^{j}$ (res. $p_{i}^{z}$ ) is the price charged by firm $i$ in region $j$ (res. region $z$ ).

Let the first element of the couple $(j z)$ represent the location choice of firm $h$ and the second the choice of firm $l$. Clearly, there are four possible combinations: (AB) with the high quality firm in region $A$ and the low quality firm in $B,(\mathrm{BA})$ with the high quality firm in region $B$ and the low quality firm in $A$, (AA) 
with both firms choosing to locate in region $A$ and finally, (BB) with both firms located in region $B$.

Let $\theta_{0}^{j}$ be the value of $\theta$ which identifies the consumer dwelling in region $j$ $(j \in\{A, B\})$ who is indifferent between not to consume and consume one unit of the low-quality product; let $\theta_{1}^{j}$ be the value of $\theta$ identifying the consumer dwelling in region $j$ who is indifferent between buying one unit of the low quality product and one unit the high quality one. The marginal consumers $\theta_{0}^{j}$ and $\theta_{1}^{j}$ take different values in correspondence of the possible location choices.

(i) Consider the case $(\mathrm{AB})$ first. In region $A$, the solution to the following equation:

$$
\theta k_{l}-p_{l}^{A}-t=0
$$

implies $\theta_{0}^{A}=\left(p_{l}^{A}+t\right) / k_{l}$, while the solution to:

$$
\theta k_{h}-p_{h}^{A}=\theta k_{l}-p_{l}^{A}-t,
$$

gives $\theta_{1}^{A}=\left(p_{h}^{A}-p_{l}^{A}-t\right) /\left(k_{h}-k_{l}\right)$. For region $B, \theta_{0}$ solves:

$$
\theta k_{l}-p_{l}^{B}=0
$$

so that $\theta_{0}^{B}=p_{l}^{B} / k_{l}$, while the indifference parameter $\theta_{1}^{B}$ follows from:

$$
\theta k_{l}-p_{l}^{B}=\theta k_{h}-p_{h}^{B}-t,
$$

that implies $\theta_{1}^{B}=\left(p_{h}^{B}-p_{l}^{B}+t\right) /\left(k_{h}-k_{l}\right)$.

By using a similar procedure, it is easy to get that: ${ }^{3}$

(ii) in case (BA), $\theta_{0}^{A}=p_{l}^{A} / k_{l}, \theta_{1}^{A}=\left(p_{h}^{A}-p_{l}^{A}+t\right) /\left(k_{h}-k_{l}\right), \theta_{0}^{B}=\left(p_{l}^{B}+\right.$ $t) / k_{l}$ and $\theta_{1}^{B}=\left(p_{h}^{B}-p_{l}^{B}-t\right) /\left(k_{h}-k_{l}\right)$;

(iii) in case (AA), $\theta_{0}^{A}=p_{l}^{A} / k_{l}, \theta_{1}^{A}=\left(p_{h}^{A}-p_{l}^{A}\right) /\left(k_{h}-k_{l}\right), \theta_{0}^{B}=\left(p_{l}^{B}+t\right) / k_{l}$ and $\theta_{1}^{B}=\left(p_{h}^{B}-p_{l}^{B}\right) /\left(k_{h}-k_{l}\right)$;

$(i v)$ in case (BB), $\theta_{0}^{A}=\left(p_{l}^{A}+t\right) / k_{l}, \theta_{1}^{A}=\left(p_{h}^{A}-p_{l}^{A}\right) /\left(k_{h}-k_{l}\right), \theta_{0}^{B}=p_{l}^{B} / k_{L}$ and $\theta_{1}^{B}=\left(p_{h}^{B}-p_{l}^{B}\right) /\left(k_{h}-k_{l}\right)$.

Notice that when firms locate in the same region, say $j$, the marginal consumers in that region are not affected by transportation costs. In the other, say $z$, the consumer indifferent between the purchase of the two variants is not affected by transportation costs neither -he has to incur them for consuming both variants. By contrast the consumer in $z$ indifferent between consuming the

\footnotetext{
${ }^{3}$ In order not to burden the notation we will not introduce another index on the marginal consumers' parameters to identify the location choices by firms: the cases will be treated separately and no confusion will arise.
} 
low-quality variant or not consuming at all is affected by the burden of transportation costs. This asymmetry will play a fundamental role in explaining the results of the paper. Notice that transportation costs will enter the analysis through equilibrium prices as well, as firms optimize taking into account their existence, but this will determine a second-order effect only.

We assume that there are no fixed costs and marginal production costs are constant and nil, moreover we assume that transportation costs are low enough to guarantee that both firms sell positive quantities of product on both markets. ${ }^{4}$ This set of assumptions serves us to focus on the study of strategic location choice, avoiding all the issues related to production and transportation technologies which, even though interesting, would shift the focus of the study away from strategic location choice.

When regions have different sizes (case (a) above), profits to the low quality producer are:

$$
\pi_{l}^{j z}=\alpha\left(\theta_{1}^{A}-\theta_{0}^{A}\right) p_{l}^{A}+\left(\theta_{1}^{B}-\theta_{0}^{B}\right) p_{l}^{B},
$$

while the profits for the high quality one:

$$
\pi_{h}^{j z}=\alpha\left(1-\theta_{1}^{A}\right) p_{h}^{A}+\left(1-\theta_{1}^{B}\right) p_{h}^{B} .
$$

When regions present a different willingness to pay (case (b) above) and the location choice is $(j z)$, profits of the firm selling the low quality variant write:

$$
\pi_{l}^{j z}=\frac{1}{\bar{\theta}}\left(\theta_{1}^{A}-\theta_{0}^{A}\right) p_{l}^{A}+\left(\theta_{1}^{B}-\theta_{0}^{B}\right) p_{l}^{B},
$$

while profits of the firm supplying the high quality one equal:

$$
\pi_{h}^{j z}=\frac{1}{\bar{\theta}}\left(\bar{\theta}-\theta_{1}^{A}\right) p_{h}^{A}+\left(1-\theta_{1}^{B}\right) p_{h}^{B} .
$$

The timing of the game is the following: in the first stage firms sequentially and irreversibly choose their location, we call the leader the firm that chooses the first and the follower the second mover. In the second stage firms simultaneously and non-cooperatively set prices given the location choices of the first stage. We opt for a sequential-move game as we are interested in studying the firms' incentives to cluster in one region region or to disperse, and the sequential location choice better fits this aim. ${ }^{5}$

\footnotetext{
${ }^{4}$ Admittedly the last assumption is rather vague: the following analysis will provide a more accurate formulation. See subsection (3.1)

${ }^{5}$ If the game were simultaneous in location choice the only difference would be multiplicity of Nash equilibria as it can be inferred by following analysis.
} 


\section{$3 \quad$ Equilibrium analysis}

In order to find the (pure-strategy) subgame perfect Nash Equilibria (SPNE) of the game will solve the model backwards, starting from the simultaneous price competition.

\subsection{Price competition}

The second stage of the game is solved through standard maximization techniques, deriving first order conditions for prices, and observing that second order conditions are always satisfied: we will not bother the reader with these calculations, reporting the second stage equilibrium prices and profits in Appendix A1 and A2. Both in the cases of different consumers masses and willingnesses to pay, in order to have positive equilibrium prices demands for the high- and the low-quality variant in all regions for all location choices we assume that $t<\frac{k_{l}\left(k_{h}-k_{l}\right)}{2 k_{h}-k_{l}}$ (see note 4$)$.

\subsection{Location choice}

In the first stage the high $(h-)$ and low $(l-)$ quality firms choose sequentially and non-cooperatively the region in which they produce. In the following we refer to location outcomes $(\mathrm{AA})$ and $(\mathrm{BB})$ as agglomeration ones and to $(\mathrm{AB})$ and (BA) as dispersion ones. Two forces play a role in determining the firms' location choices: we label the first one competitive effect and the second one is the market potential effect.

In order to better understand the former of these two forces, firstly consider the case of identical regions (i.e. $\alpha=1$ and $\bar{\theta}=1$ ) so that all effects coming from asymmetries between markets are neutralized. Since dispersion is a way to relax price competition through transportation costs, when firms choose to locate in different regions, they realize higher equilibrium profits than in the case in which both products are manufactured in the same region. This emerges simply by observing that the difference between equilibrium profits realized under dispersion and agglomeration is strictly positive. Indeed we get that:

$$
\pi_{h}^{B A}-\pi_{h}^{A A}=\pi_{l}^{A B}-\pi_{l}^{A A}=\frac{2 k_{h}\left(2 k_{h}-k_{l}\right) t^{2}}{\left(k_{h}-k_{l}\right)\left(4 k_{h}-k_{l}\right)^{2}} .
$$

Therefore, in absence of any asymmetry, firms are better off dispersing than agglomerating. Consider, for example, the choice of the $h$-firm if the $l$-one is in $A$ : "moving" from (BA) to (AA) implies a decrease of the profits realized in region $B$ that is not compensated by the increase of the profits in region $A$. The 
same argument applies to any other agglomeration outcome for firm $h$ as well as for firm $l$. Observe that the incentive to dispersion is equal for both firms; they earn higher profits in the region to which they "move", but "lose" profits in the region they leave. However, there is slight difference between the two producers: when "moving" from a dispersion to an agglomeration location the gains and losses for the high-quality firm are both higher than the ones for the low-quality firm. This feature, which is irrelevant in case of symmetric locations (gains cancel out with losses for both firms) plays a crucial role when regions differ in terms of market size.

Finally notice that dispersion incentives are increasing with the extent of transportation costs: with positive transportation $\operatorname{costs}^{6}$ and symmetric regions, firms prefer dispersion: their role in loosening competition is crucial. Indeed locating "far away" from the competitor, i.e. choosing dispersion, reduces the competitiveness of the firms on both export markets, since transportation costs distort prices, and hence, symmetrically, strengthens the position of each firm in its own location.

The other force that influences equilibrium outcomes, namely the market potential effect, stems out from market size and willingness to pay asymmetries which render region $A$ a priori better than the other for each agent. Indeed, if firms were monopolists on the market, so that the competition effect would disappear, each one would prefer to locate in region $A$ and to export the good to region $B$. The bigger consumer mass in that region or its consumers' higher willingness to pay would be better exploited without distorting $A$-dwellers choices through transportation costs. ${ }^{7}$

Each firm will hence face a trade-off between the competition and market potential effects, the latter pushing firms to locate in region $A$ as long as $\theta$ or $\alpha$ are bigger than unity, and the former pushing them to locate one far away from the other. The resulting of these two forces will determine equilibrium outcomes.

We treat separately how regions' asymmetries in terms of market size and willingness to pay influence firms' location choices.

\footnotetext{
${ }^{6}$ When $t=0$, namely transportation costs are absent, the two locations collapse into one and hence the distinction between dispersion and agglomeration is immaterial

${ }^{7}$ To ascertain this point, the reader can consider the location choices of a single-variant monopolist alternatively when $\alpha$ and $\bar{\theta}$ exceed unity. Both with size and income asymmetries, the unique optimal choice of such an agent is to locate in region $A$ and to export in $B$. The interested reader can formally solve this case as an exercise, although calculations are available.
} 


\subsubsection{Different market size}

Assume that regions have different size, i.e. $\alpha>1$. In such a case, the benefit to locate in the larger region arises for both firms. Clearly, this implies that, if one of the two firms is located in the smaller region, the other prefers to locate in the larger one since the benefit of dispersion would be reinforced by the convenience of trading in a larger market. Indeed it is easy to check that $\pi_{h}^{A B}>\pi_{h}^{B B}$ and $\pi_{l}^{B A}>\pi_{l}^{B B}$ for all $\alpha>1$. Similarly, each firm, at a dispersion equilibrium, prefers to locate in the larger region: $\pi_{h}^{A B}>\pi_{h}^{B A}$ and $\pi_{l}^{B A}>\pi_{l}^{A B}$.

More interestingly, if one firm is located in the larger region, the choice of the other one depends on the extent of asymmetry in terms of consumers' mass. Comparing $\pi_{h}^{A A}$ with $\pi_{h}^{B A}$ and $\pi_{l}^{A A}$ with $\pi_{l}^{A B}$, we get that: ${ }^{8}$

$$
\begin{aligned}
& \pi_{h}^{A A}-\pi_{h}^{B A} \gtreqless 0 \text { iff } \alpha \gtreqless \alpha_{1}=\frac{4 k_{h}\left(k_{h}-k_{l}\right)+k_{l} t}{4 k_{h}\left(k_{h}-k_{l}\right)+k_{l} t-2 k_{h} t}, \\
& \pi_{l}^{A A}-\pi_{l}^{A B} \gtreqless 0 \text { iff } \alpha \gtreqless \alpha_{2}=\frac{2 k_{l}\left(k_{h}-k_{l}\right)+3 k_{l} t-2 k_{h} t}{2 k_{l}\left(k_{h}-k_{l}\right)+k_{l} t-2 k_{h} t} .
\end{aligned}
$$

Observe that $\alpha_{2}>\alpha_{1}>1$.

The results are summarized as follows:

Proposition 1 Let $\alpha>1$, then

(i) If $1<\alpha<\alpha_{1}$, there are two possible equilibria, at which location choice exhibits dispersion: $(A B)$ and $(B A)$, the leader choosing region $A$.

(ii) If $\alpha_{1}<\alpha<\alpha_{2}$, independently on the order of moves, the equilibrium is unique and exhibits dispersion, the firms' location choice is (AB).

(iii) If $\alpha>\alpha_{2}$, the equilibrium is unique and exhibits agglomeration: the equilibrium location choice is (AA).

Proof. Remember that $\pi_{h}^{A B}>\pi_{h}^{B B}$ and $\pi_{l}^{B A}>\pi_{l}^{B B}, \pi_{h}^{A B}>\pi_{h}^{B A}$ and $\pi_{l}^{B A}>\pi_{l}^{A B}$ for all $\alpha>1$ and $t>0$.

(i) Assume that $1<\alpha<\alpha_{1}$, from the previous inequalities we obtain $\pi_{h}^{A B}>$ $\pi_{h}^{B A}>\pi_{h}^{A A}$ and $\pi_{h}^{A B}>\pi_{h}^{B B}$ for the $h$-firm, and similarly, $\pi_{l}^{B A}>\pi_{l}^{A B}>\pi_{l}^{A A}$ and $\pi_{l}^{B A}>\pi_{l}^{B B}$ for the $l$-firm. It is clear that if the role of the leader is played by the high-quality firm, it will choose region $A$. Hence the low-quality producer will find optimal to choose region $B$. A similar reasoning applies if the leader is the low-quality firm: it will choose region $A$ leaving region $B$ to its rival.

(ii) If $\alpha_{1}<\alpha<\alpha_{2}$, then we have that $\pi_{h}^{A A}>\pi_{h}^{B A}, \pi_{h}^{A B}>\pi_{h}^{B B}$ and $\pi_{h}^{A B}>$ $\pi_{h}^{B A}$ for the $h$-quality producer, while $\pi_{l}^{B A}>\pi_{l}^{A B}>\pi_{l}^{A A}$ and $\pi_{l}^{B A}>\pi_{l}^{B B}$ for

\footnotetext{
${ }^{8}$ See Appendix A1.
} 
the $l$-quality producer. The high-quality firm has a dominant strategy choosing region $A$, consequently the low-quality producer selects region $B$ both acting as a leader or as a follower.

(iii) Move finally to the case $\alpha>\alpha_{2}$. For the high-quality we have that $\pi_{h}^{A B}>\pi_{h}^{B B}, \pi_{h}^{A B}>\pi_{h}^{B A}$ and $\pi_{h}^{A A}>\pi_{h}^{B A}$. Similarly, for the low-quality firm: $\pi_{l}^{B A}>\pi_{l}^{B B}, \pi_{l}^{B A}>\pi_{l}^{A B}$ and $\pi_{l}^{A A}>\pi_{l}^{A B}$. Both firms have a dominant strategy: locating in region $A$ irrespective of the decision of their rival.

First of all, notice that when locations differ because of consumer masses, equilibrium prices in the two locations are not affected by $\alpha$, that measures the extent of asymmetry in terms of market size (see Appendix A1); consequently, an increase in the consumer mass in $A$ does not influence the firm's incentives to disperse, which act through price competition.

Remember that the higher is $\alpha$ the higher the incentive to locate in region $A$ for both firms. When the difference in size between the two regions is "small" (i.e. $1<\alpha<\alpha_{1}$ ) the competitive effect overwhelms the market potential one: the first firm choosing location selects the (slightly) more advantageous one, $A$, and the second mover is forced by the competitive effect to locate in region $B$. As $\alpha$ increases, the market potential effect becomes more and more important and the incentives to locate in region $A$ increase for both firms, irrespective of the presence of the other agent, but the incentives are always bigger for the high-quality firm; indeed one can check that:

$$
\pi_{h}^{A A}-\pi_{h}^{B A}>\pi_{l}^{A A}-\pi_{l}^{A B}, \text { for any } t>0 \text { and } \alpha>1 .
$$

To firm $h$ hence, it becomes more profitable to select region $A$ in larger intervals for $\alpha$, no matter what is the (preceding or following) choice of its rival. By calculating the partial derivatives one can show that the incentives to agglomerate in region $A$ increase faster with $\alpha$ for the high-quality firm:

$$
\frac{\partial\left(\pi_{l}^{A A}-\pi_{l}^{A B}\right)}{\partial \alpha}<\frac{\partial\left(\pi_{h}^{A A}-\pi_{h}^{B A}\right)}{\partial \alpha} .
$$

When $\alpha$ increases, profits earned by firms in region $A$ grow in configurations $(\mathrm{AA})$ and $(\mathrm{BA})$ for the high-quality firm and in $(\mathrm{AA})$ and $(\mathrm{AB})$ for the lowquality one, but at a higher rate for the former.

This depends on the fact that, as it is shown above, the gain realized in region $A$ when the high-quality firm moves from (AB) to (AA) is larger than the one obtained by the low-quality firm when it moves from (BA) to (AA), and the increases in $\alpha$ increase this gap. ${ }^{9}$ The intuition for this asymmetry has to

\footnotetext{
${ }^{9}$ We could conclude that it is more costly for a $l$-firm than for a $h$-firm to locate close to a rival firm.
} 
be found in the "intrinsic advantage" the higher quality producers enjoy over low-quality ones in models of vertical product differentiation with symmetric marginal production costs.

If $\alpha_{1}<\alpha<\alpha_{2}$, the high-quality firm has a dominant move in choosing location $A$ : the higher volume of potential sales in region $A$ increase the opportunity cost of avoiding direct competition with the low-quality producer up to a point in which it is more profitable to -possibly- agglomerate in $A$. Dispersion forces (the competitive effect) still rule the location choices of the low-quality firm. Hence the latter settles, independently on the fact of being leader or follower, in the region not occupied by the $h$-firm.

Finally, when $\alpha$ exceeds $\alpha_{2}$, agglomerating in $A$ is a dominant move for the $l$-firm as well, as the market potential effect overwhelms the competitive one for this agent too: at the only SPNE of the game firms agglomerate in region $A$.

\subsubsection{Different willingness to pay}

Move now to the analysis of regions characterized by different willingnesses to pay. The uniform distribution of consumer types along the support implies that the average willingness to pay in $A$ is $\frac{\bar{\theta}}{2}$, while in $B$ it is $\frac{1}{2}$; clearly $\frac{\bar{\theta}}{2}>\frac{1}{2}$ as $\bar{\theta}>1$. As we pointed out in the introduction, an agent's higher willingness to pay can be interpreted as a larger income of that agent, hence region $A$ is characterized by a larger average income than region $B$; moreover the least willingness to pay -and so income- in both regions is the same: region $A$ is richer than region $B$.

If one of the two firms is located in the poorer region $(B)$, the other prefers to locate in the richer one since -similarly to the previous case- the benefit of dispersion would be reinforced by the convenience of trading directly in a market with consumers characterized by a higher willingness to pay. Indeed $\pi_{h}^{A B}>\pi_{h}^{B B}$ and $\pi_{l}^{B A}>\pi_{l}^{B B}$ for all $\bar{\theta}>1$.

Moreover, each firm, at a dispersion equilibrium, prefers to locate in the larger region: $\pi_{h}^{A B}>\pi_{h}^{B A}$ and $\pi_{l}^{B A}>\pi_{l}^{A B}$. More interestingly, if one firm is located in the richer region, the choice of the other one depends on the extent of asymmetry in terms of consumers' preferences. As it is shown in Appendix A2, by comparing $\pi_{h}^{B A}$ with $\pi_{h}^{A A}$ and $\pi_{l}^{A A}$ with $\pi_{l}^{A B}$, we get, for the high-quality firm:

$$
\pi_{h}^{A A}-\pi_{h}^{B A}<0 \text { for all } \bar{\theta}>1 .
$$

For the low-quality one, assuming that the quality difference between the two 
producers is large enough, ${ }^{10}$ we have:

$$
\pi_{l}^{A A}-\pi_{l}^{A B} \lesseqgtr 0 \text { iff } \bar{\theta} \lesseqgtr \bar{\theta}_{1}=\frac{\left(2 k_{h}-k_{l}\right)}{\left(2 k_{h}-3 k_{l}\right)} .
$$

Our results are again summarized as follows:

Proposition 2 Let $\theta>1$ and $k_{h}>\frac{3}{2} k_{l}$, then

(i) If $1<\bar{\theta}<\bar{\theta}_{1}$, the game has two equilibria and both exhibit dispersion. The possible location choices are $(A B)$ or $(B A)$, the leader choosing region $A$.

(ii) If $\bar{\theta}>\bar{\theta}_{1}$, independently of the order of moves, there is a unique equilibrium which exhibits dispersion: location choice is (BA).

Proof. Remember that $\pi_{h}^{A B}>\pi_{h}^{B B}$ and $\pi_{l}^{B A}>\pi_{l}^{B B}, \pi_{h}^{A B}>\pi_{h}^{B A}$ and $\pi_{l}^{B A}>\pi_{l}^{A B}$ for all $\bar{\theta}>1$ and $t>0$.

(i) When $1 \leqslant \bar{\theta}<\bar{\theta}_{1}$, from the previous inequalities we obtain $\pi_{h}^{A B}>$ $\pi_{h}^{B A}>\pi_{h}^{A A}$ and $\pi_{h}^{A B}>\pi_{h}^{B B}$ for the $h$-firm, and similarly, $\pi_{l}^{B A}>\pi_{l}^{A B}>\pi_{l}^{A A}$ and $\pi_{l}^{B A}>\pi_{l}^{B B}$ for the $l$-firm. Observe that both firms tend to locate in different regions because they prefer dispersion to agglomeration. Thus the only equilibrium is for the first mover to choose region $A$ and for the follower to choose region $B$. Obviously, the leader takes advantage of moving first by locating in the richer region;

(ii) If $\bar{\theta}>\bar{\theta}_{1}$, we still have that $\pi_{h}^{A B}>\pi_{h}^{B A}>\pi_{h}^{A A}$ and $\pi_{h}^{A B}>\pi_{h}^{B B}$ for the $h$-firm, while $\pi_{l}^{B A}>\pi_{l}^{B B}, \pi_{l}^{B A}>\pi_{l}^{A B}$ and $\pi_{l}^{A A}>\pi_{l}^{A B}$ for the $l$-quality producer. Hence, locating in region $A$ represents a dominant move for the low quality producer. Therefore, even if the high quality firm moves first, knowing that the $l$-firm always plays the dominant move, the $h$-firm will choose to locate in region $B$.

According to proposition 2, when the difference in income between the two regions is small, so that the regions are almost equally wealthy, the competitive effect overwhelms the market potential one: the leader still prefers to grasp the opportunity to settle in the -slightly- richer region A, and the follower prefers to avoid direct competition both in $A$ and in $B$ choosing the -slightly- poorer region B. As $\bar{\theta}$ grows, for both firms the opportunity cost to disperse in region $B$ if the rival is in $A$ becomes higher and higher. Nonetheless for the high-quality firm the competitive effect still rules: if the other firm is already settled in $A$ it is still worth to disperse in $B$. By contrast, the market potential effects takes

\footnotetext{
${ }^{10}$ We assume that $k_{h}>\frac{3}{2} k_{l}$. If $k_{h}<\frac{3}{2} k_{l}$ then the only equilibrium outcome as for location choice is the one proposed in part ( $i$ ) of Proposition 2.
} 
over for the low-quality firm when $\bar{\theta}$ exceeds $\bar{\theta}_{1}$, so that this agent prefers to settle in region $A$ even if its rival is already there or will choose to be there. It is easy to check that the incentives to agglomerate in $A$ are higher for the low-quality producer:

$$
\pi_{h}^{A A}-\pi_{h}^{B A}<\pi_{l}^{A A}-\pi_{l}^{A B}, \text { for any } t>0 \text { and } \bar{\theta}>1,
$$

It can be checked that

$$
\frac{\partial\left(\pi_{l}^{A A}-\pi_{l}^{A B}\right)}{\partial \bar{\theta}}>\frac{\partial\left(\pi_{h}^{A A}-\pi_{h}^{B A}\right)}{\partial \bar{\theta}}
$$

Intuitively, this depends on the fact that when $\bar{\theta}$ increases, the high-quality firm is able to exploit more easily the power deriving from the higher quality of the good it sells by minimizing the (negative) impact of transportation costs on the profits realized in the market $A$ at location (BA). The reason for this asymmetry between the two firms can be found in the observation we proposed after the identification of the marginal consumers in the previous section. By locating in region $B$ if the high-quality producer is in $A$, the low-quality producer knows that transportation costs will influence the position of the consumer who is indifferent between purchasing the low-quality variant and the high-quality one as well as of the position of the consumer indifferent between consuming the low-quality variant and not consuming in market $A$. Both these effects influence negatively the profits of the low-quality producer, on one side making less consumers willing to consume at all, and on the other side making consumers shift from the low- to the high-quality variant. When the richness of $A$ 's consumers becomes grater and greater this double source of distortion deriving form locating in $B$ becomes a too heavy burden to be paid, and choosing region $A$ both as a leader or as a follower results a dominant action. On the contrary, the high-quality producer, locating in $B$ if its rival is in $A$, dampens competition in region $B$ and suffers a distortion due to transportation costs on the left-end of its demand only. ${ }^{11}$

This effect is in principle present in the scenario in which firms differ because of market size as well, but there is a fundamental difference in the two cases. Indeed in the case in which regions differ because of consumers' size

\footnotetext{
${ }^{11}$ This point can be ascertained by working out a model in which the left end of the lowquality firm's demand is not affected by transportation costs on its export market, so that their only influence is in the determination of the border between the high- and the low-quality demand. In this model the only equilibrium exhibits dispersion. The same result holds for a model in which the market is covered: by assumption all consumers buy one unit of the good so endogenously transportation costs do not influence the left end of the low-quality firm's demand. Both types of model are available upon request.
} 
the asymmetry parameter $\alpha$ does not influence equilibrium prices in location $A$ (see Appendix A1), and hence does not affect marginal consumers and demand repartition between firms in that region. By contrast, when regions differ because of the wealth of their consumers, the parameter $\bar{\theta}$, which identifies the upper bound of the quality appreciation distribution, does influence equilibrium prices (see Appendix A2) and hence marginal consumers and demand repartition between firms in market in $A$. The interaction of $\bar{\theta}$ and $t$ in determining the prices drives the results. Since the incentive to agglomerate stops growing as $\bar{\theta}$ becomes infinitely large, it is important to check what happens to this limit case for both firms; we get that:

$$
\begin{gathered}
\lim _{\bar{\theta} \rightarrow \infty}\left(\pi_{h}^{A A}-\pi_{h}^{B A}\right)=-\frac{\left(2 k_{h}-k_{l}\right) k_{l} t^{2}}{\left(k_{h}-k_{l}\right)\left(4 k_{h}-k_{l}\right)^{2}}<0, \\
\lim _{\bar{\theta} \rightarrow \infty}\left(\pi_{h}^{A A}-\pi_{h}^{B A}\right)=\frac{\left(2 k_{h}-3 k_{l}\right)\left(2 k_{h}-k_{l}\right) k_{h} t^{2}}{\left(k_{h}-k_{l}\right)\left(4 k_{h}-k_{l}\right)^{2} k_{l}}>0 .
\end{gathered}
$$

The $h$-firm never prefers agglomeration in $A$ to dispersion.

When $\bar{\theta}>\bar{\theta}_{1}$, locating in $A$ becomes a dominant move for the low-quality firm. Consequently, if the $h$-firm moves first, it anticipates the choice of the $l$-firm by choosing to settle in region $B$.

\section{Welfare analysis}

Let us turn to welfare analysis; our aim is to determine the socially optimal location, that is the location in correspondence of which the aggregate social welfare is maximized by a benevolent social planner. Because of our focus on location, we assume that the social planner is unable to influence the pricing behavior of the firms but can impose location selection. The measure for social welfare we adopt in this paper is the standard one in vertical differentiation analysis: we add up consumers' surplus and firms' profits over the two regions, subtracting transportation costs. The explicit functional form of the welfare measure can be found in the appendices A3 and A4.

\subsection{Different market size}

When regions differ in the market size, the comparison between locations in terms of social welfare gives us the following result:

Proposition 3 Let $\alpha>1$, then the socially optimal location choice is

(i) (AB) iff $1<\alpha<\alpha_{3}$;

(ii) (AA) iff $\alpha_{3}<\alpha$. 
Proof. See Appendix A3.

The value of $\alpha_{3}$ can be found in Appendix A3.

To give an intuition to these results, notice first that it can be proved that, when regions are completely identical, social welfare under dispersion is larger than under agglomeration. ${ }^{12}$ When the market size is similar between the two regions (i.e. $1<\alpha<\alpha_{3}$ ), this result continues to hold. However, social welfare is larger in $(\mathrm{AB})$ than in $(\mathrm{BA})$ : in order to consume the high-quality good, transportation costs have to be paid by consumers of region $B$ when the location choice is $(\mathrm{AB})$ and by consumers of region $A$ when firms' location is (BA); since region $A$ is more populated, locating the $h$-firm in region $A$ allows a larger mass of consumers to select that variant -as they do not have to pay transportation costs for it- Symmetrically, the appeal of the low-quality variant in $A$ is reduced by the presence of the transportation cost. The distortional effect of transportation costs on the purchase of the $h$-good is minimized in $(\mathrm{AB})$.

When the market size of region $A$ becomes large enough (i.e. $\alpha>\alpha_{3}$ ), the component of social welfare in region $A$ plays an important role in explaining why it is desirable to agglomerate the production of the two variants in this region from a social point of view. By doing so transportation cost do not directly ${ }^{13}$ determine the consumer indifferent between the high- and the lowquality variant neither in region $A$ nor in region $B$. With respect to the (AB) configuration this implies a reduction of the demand for the high-quality in $A$ but an increase in $B$, but simultaneously an increase in the number of consumers who purchase the $l$-variant in the larger location (and who did not consume under configuration $(\mathrm{AB}))$ as they do not have to pay transportation costs longer. By the same argument -inverted- some consumers in the left-end of the distribution in the small region $B$ shift to no-consumption. The balance of these effects determines the social preference for location outcome (AA).

Finally, let us consider the threshold values of the market size in correspondence of which there is a switch from dispersion to agglomeration in the decentralized economy and in the social optimum. By direct comparison between $\alpha_{3}$ and $\alpha_{2}$, we get the following:

Remark 1 Let $\alpha>1$, then

$$
\alpha_{3}>\alpha_{2} \text {. }
$$

\footnotetext{
${ }^{12}$ Clearly in this case location outcomes (AB) or (BA) lead to the same welfare level.

${ }^{13}$ Transportation costs enter equilibrium prices, but this is a second order effect.
} 
Some observations are worth. First, when regions are almost equal $\left(\alpha<\alpha_{1}\right)$ oligopolistic competition may drive to an equilibrium which exhibits "bad" dispersion: if the leader is the low-quality firm then the expected outcome is (BA), which is not optimal. By contrast if the leader is the $h$-firm, unconstrained competition leads to the optimal equilibrium locations. Second, when $\alpha_{2}<\alpha<\alpha_{3}$, firms inefficiently agglomerate in region $A$. Interestingly, however, when $\alpha_{1}<\alpha<\alpha_{2}$ or $\alpha_{3}<\alpha$, unregulated oligopolistic behavior leads to socially optimal location choices. ${ }^{14}$

\subsection{Different willingness to pay}

When regions differ in the willingness to pay we get the following result:

Proposition 4 Let $\theta>1$ and $k_{h}>\frac{3}{2} k_{l}$, then the socially optimal location is $(B A)$.

Proof. See Appendix A4.

The socially optimal location in case of different willingnesses to pay for quality between regions is unique for all degrees of asymmetry and prescribes to locate the high-quality producer in the poorer region and the low-quality producer in the richer one.

Some intuitive insight into this result may be obtained by observing that, with null marginal costs of production, the location choice in correspondence of which the purchase of the high-quality good is more viable, is also the one that maximizes welfare. Now, focus on the production of the high-quality good. Since the activity of transportation is costly and directly affects the welfare of the consumers residing in the region that imports the good, by reducing their utility, it is desirable that transportation costs are paid by the consumers with higher willingness to pay. Now, (BA) is the location choice that minimizes the distortionary effect of transportation costs on the purchase of the highquality good. In fact, for buying the $h$-good when firms' location is (BA), transportation costs are only paid by the residents in region $A$, who exhibit a higher willingness to pay for quality. Symmetrically, locating the $l$-firm in region $A$ reduces -because of the transportation cost- the appeal of its variant to the dwellers of region $B$, making a higher share of them opt for the high-quality product, whose consumption generates higher utility.

Finally notice that, interestingly, there is coincidence -as far as location choices

\footnotetext{
${ }^{14}$ The distortion due to oligopoly pricing remains.
} 
are concerned- between the oligopolistic outcome and the socially optimal one, as long as the difference in wealth between regions is large enough $\left(\bar{\theta}>\bar{\theta}_{1}\right)$. By contrast, market equilibrium is socially optimal when $1<\bar{\theta}<\bar{\theta}_{1}$ if and only if the leader is the low-quality producer.

\section{Discussion}

A first interesting difference in the two cases analyzed concerns the "aggregate" equilibrium location outcomes dispersion vs. agglomeration. In both cases, a "limited" asymmetry between countries leads to dispersion at equilibrium; but, as asymmetry increases, in the case of different consumers' masses the only outcome becomes agglomeration, while in the case of different willingnesses to pay dispersion is still expected. As a consequence, differences in income between locations cannot explain the creation of industrial clusters, at least in our model in which technological issues are excluded.

Disentangling now the specific firms' location choices at equilibrium, it is worth to emphasize the striking result that when a region is "much richer" than the other $^{15}$ (see part (ii) of Proposition 2) then at the only equilibrium of the game the high-quality firm settles in the poorer region, even if it is the first to choose location, leaving the richer to its rival. It is interesting to apply this result to a scenario of trade liberalization. Imagine, to this end, a situation in which, for some reason, both firms are installed in region A under a closed economy regime -suppose, for example, that transportation costs are prohibitively high. Assume now that, at a certain date, trade between locations $A$ and $B$ becomes possible for both firms -for example a technological improvement dramatically and exogenously lowers transportation costs. Our model suggests that not only trade would emerge between the two locations, but that firms would -in absence of fixed costs- relocate too. If region $B$ is "much poorer" than region $A$, the firm that would leave the wealthy location is the high-quality producer. Of course our story abstracts from technological asymmetries between firms, presence of fixed costs at plant level, and more importantly region-specific production factor characteristics (e.g. presence of skilled work force, lower labor costs or more sophisticated technologies available...). Still this result, as well as the other ones, univocally points out the effects of pure strategic location choice.

Finally, consider the welfare implications of our analysis. A first interesting remark is that there are significant parametric regions in which unconstrained

\footnotetext{
${ }^{15}$ And variants are "differentiated enough"
} 
oligopolistic competition yields to the socially optimal location choices. In addition, in all the parametric regions which display multiple equilibria, one equilibrium is socially optimal. A benevolent social planner can hence play a "minimal role" just imposing to firms the appropriate decision ordering, so that the consequent strategic behavior leads to the social optimum. Yet, there remains a parametric situation (namely when $\alpha_{2}<\alpha<\alpha_{3}$ in the case of different market sizes) in which strategic behavior is unable to generate to socially optimal locations, and hence a more active role for the social planner is called for.

\section{Conclusion}

This paper analyzes the effects of differences in the willingness to pay and the market size on the allocation of industrial activity in a vertically differentiated oligopoly. We consider a two-stage location-price game with the following timing: in the first stage firms sequentially choose their location, and in the second stage they simultaneously and non-cooperatively set prices given the location choices of the first stage. The location decision is crucially determined by the trade-off between the competition and the market potential effects. We show that this trade-off is differently faced by the high- and low-quality producers; we capture different firms' incentives by analyzing a game in which location choices are sequential.

We have restricted our analysis to a context in which the quality levels of variants are exogenous, as well as transportation costs. Interesting extensions would be to make the quality choice endogenous and to deal with a more developed treatment of transportation costs. The analysis of these issues is in our agenda. 


\section{References}

[1] Andaluz, J. (2000). "On protection and vertical product differentiation", Regional Science and Urban Economics, 30, 77-97.

[2] Anderson, S. P. and D. J. Neven (1991). "Cournot Competition Yields Spatial Agglomeration", International Economic Review, 32, 793-808.

[3] D'Aspremont, C., J. J. Gabszewicz and J.-F. Thisse (1979). "On Hotelling's Stability In Competition", Econometrica, 47, 1145-1150.

[4] D'Aspremont, C., J. J. Gabszewicz and J.-F. Thisse (1983). "Product Differences and Prices", Economics Letters, 11, 19-23.

[5] De Palma, A., V. Ginsburgh, Y. Y. Papageorgiou and J.-F. Thisse (1985). "The principle of minimum differentiation holds under sufficient heterogeneity", Econometrica, 53, 767-781.

[6] Friedman, J. W. and J.-F. Thisse (1993). "Partial collusion fosters minimum differentiation", Rand Journal of Economics, 24, 631-645.

[7] Fujita, M., P. Krugman and A. J. Venables (1999). "The Spatial Economy. Cities, Regions, and International Trade", MIT Press.

[8] Hamilton, J. H., J.-F. Thisse and A. Weskamp (1989). "Spatial Discrimination. Bertrand vs. Cournot in a Model of Location Choice", Regional Science and Urban Economics, 19, 87-102.

[9] Hotelling, H. (1929). "Stability In Competition", Economic Journal, 39, 41-57.

[10] Jehiel, P. (1992). "Product differentiation and price collusion", International Journal of Industrial Organization, 10, 633-643.

[11] Kats, A. (1995). "More on Hotelling's stability in competition", International Journal of Industrial Organization, 13, 89-93.

[12] Krugman, P. (1980). "Scale Economies, Product Differentiation, and the Pattern of Trade", American Economic Review, 70, 950-959.

[13] Krugman, P. (1991). "Increasing Returns and Economic Geography", Journal of Political Economy, 99, 483-499.

[14] Mussa, M. and S. Rosen (1978). "Monopoly and Product Quality", Journal od Economic Theory, 18, 301-317. 
[15] Pal, D. (1998). "Does Cournot competition yield spatial agglomeration?", Economics Letters, 60, 49-53.

[16] Schmitt, N. (1995). "Product imitation, product differentiation and international trade", International Economic Review, 36, 503-608. 


\section{Appendix A1}

In this Appendix, we report the equilibrium prices and profits when locations have different consumer masses. In location choice $(\mathrm{AB})$ we have:

$$
\begin{gathered}
p_{l}^{A *}=\frac{k_{l}\left(k_{h}-k_{l}\right)-t\left(2 k_{h}-k_{l}\right)}{4 k_{h}-k_{l}}, p_{h}^{A *}=\frac{2 k_{h}\left(k_{h}-k_{l}\right)+t k_{h}}{4 k_{h}-k_{l}}, \\
p_{l}^{B *}=\frac{k_{l}\left(k_{h}-k_{l}+t\right)}{4 k_{h}-k_{l}}, p_{h}^{B *}=\frac{2 k_{h}\left(k_{h}-k_{l}+t\right)}{4 k_{h}-k_{l}}-t .
\end{gathered}
$$

In location choice (BA):

$$
\begin{gathered}
p_{l}^{A *}=\frac{k_{l}\left(k_{h}-k_{l}+t\right)}{4 k_{h}-k_{l}}, p_{h}^{A *}=\frac{2 k_{h}\left(k_{h}-k_{l}+t\right)}{4 k_{h}-k_{l}}-t, \\
p_{l}^{B *}=\frac{k_{l}\left(k_{h}-k_{l}\right)-t\left(2 k_{h}-k_{l}\right)}{4 k_{h}-k_{l}}, p_{h}^{B *}=\frac{2 k_{h}\left(k_{h}-k_{l}\right)+t k_{h}}{4 k_{h}-k_{l}} .
\end{gathered}
$$

In location choice (AA):

$$
\begin{gathered}
p_{l}^{A *}=\frac{k_{l}\left(k_{h}-k_{l}\right)}{4 k_{h}-k_{l}}, p_{h}^{A *}=\frac{2 k_{h}\left(k_{h}-k_{l}\right)}{4 k_{h}-k_{l}}, \\
p_{l}^{B *}=\frac{\left(k_{h}-k_{l}\right)\left(k_{l}-2 t\right)}{4 k_{h}-k_{l}}, p_{h}^{B *}=\frac{\left(k_{h}-k_{l}\right)\left(2 k_{h}-t\right)}{4 k_{h}-k_{l}} .
\end{gathered}
$$

Finally, in location choice (BB):

$$
\begin{gathered}
p_{l}^{A *}=\frac{\left(k_{h}-k_{l}\right)\left(k_{l}-2 t\right)}{4 k_{h}-k_{l}}, p_{h}^{A *}=\frac{\left(k_{h}-k_{l}\right)\left(2 k_{h}-t\right)}{4 k_{h}-k_{l}}, \\
p_{l}^{B *}=\frac{k_{l}\left(k_{h}-k_{l}\right)}{4 k_{h}-k_{l}}, p_{h}^{B *}=\frac{2 k_{h}\left(k_{h}-k_{l}\right)}{4 k_{h}-k_{l}} .
\end{gathered}
$$

As a standard result, equilibrium prices are unaffected by the different consumers' mass between regions.

We restrict the analysis to the case in which transportation costs are low enough to keep all the equilibrium prices and quantities positive, i.e. $t<$ $\frac{k_{l}\left(k_{h}-k_{l}\right)}{2 k_{h}-k_{l}}$.

By using eq. (3), (4) and (A1.1)-(A1.8), we obtain the equilibrium profits 
realized in correspondence of each location choices:

$\pi_{l}^{A B}=\frac{k_{h}\left\{k_{l}^{2}\left(k_{l}-t\right)^{2}(1+\alpha)-2 k_{h} k_{l}\left(k_{l}-t\right)\left(k_{l}+k_{l} \alpha-2 t \alpha\right)+k_{h}^{2}\left[4 t^{2} \alpha-4 t \alpha k_{l}+k_{l}^{2}(1+\alpha)\right]\right\}}{\left(k_{h}-k_{l}\right) k_{l}\left(4 k_{h}-k_{l}\right)^{2}}$,

$\pi_{h}^{A B}=\frac{\left\{k_{l}^{2} t^{2}-4 k_{l} k_{h} t\left(k_{l}+t\right)+4 k_{h}^{4}(1+\alpha)-4 k_{h}^{3}\left[2 k_{l}(1+\alpha)-t(\alpha-2)\right]+k_{h}^{2}\left[4 k_{l}^{2}(1+\alpha)+t^{2}(4+\alpha)-4 k_{l} t(\alpha-3)\right]\right\}}{\left(k_{h}-k_{l}\right)\left(4 k_{h}-k_{l}\right)^{2}}$,

$\pi_{l}^{B A}=\frac{k_{h}\left\{k_{l}^{2}\left(k_{l}-t\right)^{2}(1+\alpha)-2 k_{h} k_{l}\left(k_{l}-t\right)\left(k_{l}+k_{l} \alpha-2 t\right)+k_{h}^{2}\left[4 t^{2}-4 t k_{l}+k_{l}^{2}(1+\alpha)\right]\right\}}{\left(k_{h}-k_{l}\right) k_{l}\left(4 k_{h}-k_{l}\right)^{2}}$,

$\pi_{h}^{B A}=\frac{\left\{\alpha k_{l}^{2} t^{2}-4 \alpha k_{l} k_{h} t\left(k_{l}+t\right)+4 k_{h}^{4}(1+\alpha)-4 k_{h}^{3}\left[2 k_{l}(1+\alpha)+t(2 \alpha-1)\right]+k_{h}^{2}\left[4 k_{l}^{2}(1+\alpha)+t^{2}(1+4 \alpha)+4 k_{l} t(3 \alpha-1)\right]\right\}}{\left(k_{h}-k_{l}\right)\left(4 k_{h}-k_{l}\right)^{2}}$,

$\pi_{l}^{A A}=\frac{k_{h}\left(k_{h}-k_{l}\right)\left[4 t^{2}+k_{l}^{2}(1+\alpha)-4 k_{l} t\right]}{k_{l}\left(4 k_{h}-k_{l}\right)^{2}}$,

$\pi_{h}^{A A}=\frac{\left(k_{h}-k_{l}\right)\left[t^{2}+4 k_{h}^{2}(1+\alpha)-4 k_{h} t\right]}{\left(4 k_{h}-k_{l}\right)^{2}}$,

$\pi_{l}^{B B}=\frac{k_{h}\left(k_{h}-k_{l}\right)\left[4 t^{2} \alpha+k_{l}^{2}(1+\alpha)-4 k_{l} t \alpha\right]}{k_{l}\left(4 k_{h}-k_{l}\right)^{2}}$,

$\pi_{h}^{B B}=\frac{\left(k_{h}-k_{l}\right)\left[\alpha t^{2}+4 k_{h}^{2}(1+\alpha)-4 k_{h} t \alpha\right]}{\left(4 k_{h}-k_{l}\right)^{2}}$.

It is easy to check that $\pi_{h}^{A B}>\pi_{h}^{B B}$ and $\pi_{l}^{B A}>\pi_{l}^{B B}$ for all $\alpha \geqslant 1$. Comparing $\pi_{h}^{B A}$ with $\pi_{h}^{A A}$ and $\pi_{l}^{A A}$ with $\pi_{l}^{A B}$ gives:

$$
\begin{aligned}
& \pi_{h}^{B A}-\pi_{h}^{A A}=\frac{\left(2 k_{h}-k_{l}\right) t\left\{2 k_{h}\left[2 k_{l}(\alpha-1)+t \alpha\right]-4 k_{h}^{2}(\alpha-1)-k_{l} t(\alpha-1)\right\}}{\left(k_{h}-k_{l}\right)\left(4 k_{h}-k_{l}\right)^{2}} \gtreqless 0 \text { iff } \alpha \lesseqgtr \alpha_{1}, \\
& \pi_{l}^{A B}-\pi_{l}^{A A}=\frac{k_{h}\left(2 k_{h}-k_{l}\right) t\left\{k_{l}\left[2 k_{l}(\alpha-1)-t(\alpha-3)\right]-2 k_{h}\left(k_{l}-t\right)(\alpha-1)\right\}}{k_{l}\left(k_{h}-k_{l}\right)\left(4 k_{h}-k_{l}\right)^{2}} \gtreqless 0 \text { iff } \alpha \lesseqgtr \alpha_{2},
\end{aligned}
$$

where $\alpha_{1}=\frac{4 k_{h}\left(k_{h}-k_{l}\right)+k_{l} t}{4 k_{h}\left(k_{h}-k_{l}\right)+k_{l} t-2 k_{h} t}$ and $\alpha_{2}=\frac{2 k_{l}\left(k_{h}-k_{l}\right)+3 k_{l} t-2 k_{h} t}{2 k_{l}\left(k_{h}-k_{l}\right)+k_{l} t-2 k_{h} t}$.

\section{Appendix A2}

In this Appendix, we report the equilibrium prices and profits when consumers have different willingness to pay. In location choice $(\mathrm{AB})$ we have:

$$
\begin{gathered}
p_{l}^{A *}=\frac{\bar{\theta} k_{l}\left(k_{h}-k_{l}\right)-t\left(2 k_{h}-k_{l}\right)}{4 k_{h}-k_{l}}, p_{h}^{A *}=\frac{2 \bar{\theta} k_{h}\left(k_{h}-k_{l}\right)+t k_{h}}{4 k_{h}-k_{l}}, \\
p_{l}^{B *}=\frac{k_{l}\left(k_{h}-k_{l}+t\right)}{4 k_{h}-k_{l}}, p_{h}^{B *}=\frac{2 k_{h}\left(k_{h}-k_{l}+t\right)}{4 k_{h}-k_{l}}-t .
\end{gathered}
$$

In location choice $(\mathrm{BA})$ :

$$
\begin{gathered}
p_{l}^{A *}=\frac{k_{l}\left[\bar{\theta}\left(k_{h}-k_{l}\right)+t\right]}{4 k_{h}-k_{l}}, p_{h}^{A *}=\frac{2 k_{h}\left[\bar{\theta}\left(k_{h}-k_{l}\right)+t\right]}{4 k_{h}-k_{l}}-t, \\
p_{l}^{B *}=\frac{k_{l}\left(k_{h}-k_{l}\right)-t\left(2 k_{h}-k_{l}\right)}{4 k_{h}-k_{l}}, p_{h}^{B *}=\frac{2 k_{h}\left(k_{h}-k_{l}\right)+t k_{h}}{4 k_{h}-k_{l}} .
\end{gathered}
$$

In location choice $(\mathrm{AA})$ :

$$
p_{l}^{A *}=\frac{\bar{\theta} k_{l}\left(k_{h}-k_{l}\right)}{4 k_{h}-k_{l}}, p_{h}^{A *}=\frac{2 \bar{\theta} k_{h}\left(k_{h}-k_{l}\right)}{4 k_{h}-k_{l}},
$$




$$
p_{l}^{B *}=\frac{\left(k_{h}-k_{l}\right)\left(k_{l}-2 t\right)}{4 k_{h}-k_{l}}, p_{h}^{B *}=\frac{\left(k_{h}-k_{l}\right)\left(2 k_{h}-t\right)}{4 k_{h}-k_{l}} .
$$

Finally, in (BB):

$$
\begin{gathered}
p_{l}^{A *}=\frac{\left(k_{h}-k_{l}\right)\left(\bar{\theta} k_{l}-2 t\right)}{4 k_{h}-k_{l}}, p_{h}^{A *}=\frac{\left(k_{h}-k_{l}\right)\left(2 \bar{\theta} k_{h}-t\right)}{4 k_{h}-k_{l}}, \\
p_{l}^{B *}=\frac{k_{l}\left(k_{h}-k_{l}\right)}{4 k_{h}-k_{l}}, p_{h}^{B *}=\frac{2 k_{h}\left(k_{h}-k_{l}\right)}{4 k_{h}-k_{l}} .
\end{gathered}
$$

From eq. (A1.1), (A1.3), (A1.5) and (A1.7) we observe that in all the possible location choices, the equilibrium prices of the high and low quality producers in region $A$ depend positively on the support of preferences in the same region, $\bar{\theta}$; in other terms, the presence of wealthier consumers in region $A$ allows firms to set higher prices in this market for both products. This translates into a positive relation between $\bar{\theta}$ and firms' equilibrium profits which are shown in the following. The assumption $t<\frac{k_{l}\left(k_{h}-k_{l}\right)}{2 k_{h}-k_{l}}$ allows to keep all the equilibrium prices positive, guaranteeing that firms are operative in all the possible location choices.

From eq. (3), (4) and (A2.1)-(A2.8), we obtain the equilibrium profits realized in correspondence of each location choices:

$$
\begin{aligned}
\pi_{l}^{A B} & =\frac{k_{h}\left\{k_{l}^{2}\left[t^{2}(1+\bar{\theta})+k_{l}^{2} \bar{\theta}(1+\bar{\theta})-4 k_{l} t \bar{\theta}\right]+k_{h}^{2}\left[4 t^{2}-4 t \bar{\theta} k_{l}+k_{l}^{2} \bar{\theta}(1+\bar{\theta})\right]-2 k_{h} k_{l}\left[2 t^{2}-4 t k_{l} \bar{\theta}+k_{l}^{2} \bar{\theta}(1+\bar{\theta})\right]\right\}}{\bar{\theta}^{2}\left(k_{h}-k_{l}\right) k_{l}\left(4 k_{h}-k_{l}\right)^{2}}, \\
\pi_{h}^{A B} & =\frac{\left\{k_{l}^{2} t^{2} \bar{\theta}-4 k_{l} k_{h} t\left(k_{l}+t\right) \bar{\theta}+4 k_{h}^{4} \bar{\theta}(1+\bar{\theta})-4 k_{h}^{3} \bar{\theta}\left[2 k_{l}(1+\bar{\theta})+t\right]+k_{h}^{2}\left[4 k_{l}^{2} \bar{\theta}(1+\bar{\theta})+t^{2}(1+4 \bar{\theta})+8 k_{l} t \bar{\theta}\right]\right\}}{\bar{\theta}\left(k_{h}-k_{l}\right)\left(4 k_{h}-k_{l}\right)^{2}}, \\
\pi_{l}^{B A} & =\frac{k_{h}\left\{4 k_{h}^{2} t^{2} \bar{\theta}-4 k_{h} k_{l} t\left(k_{h}+t\right) \bar{\theta}+k_{l}^{4} \bar{\theta}(1+\bar{\theta})-2 k_{l}^{3} \bar{\theta}\left(k_{h}+2 t+\bar{\theta} k_{h}\right)+k_{l}^{2}\left[8 k_{h} t \bar{\theta}+t^{2}(1+\bar{\theta})+k_{h}^{2} \bar{\theta}(1+\bar{\theta})\right]\right\}}{\bar{\theta}\left(k_{h}-k_{l}\right) k_{l}\left(4 k_{h}-k_{l}\right)^{2}} \\
\pi_{h}^{B A} & =\frac{\left\{k_{l}^{2} t^{2}-4 k_{l} k_{h} t\left(\bar{\theta} k_{l}+t\right) \bar{\theta}+4 k_{h}^{4} \bar{\theta}(1+\bar{\theta})-4 k_{h}^{3} \bar{\theta}\left[2 k_{l}(1+\bar{\theta})+t\right]+k_{h}^{2}\left[4 k_{l}^{2} \bar{\theta}(1+\bar{\theta})+t^{2}(4+\bar{\theta})+8 k_{l} t \bar{\theta}\right]\right\}}{\bar{\theta}\left(k_{h}-k_{l}\right)\left(4 k_{h}-k_{l}\right)^{2}} \\
\pi_{l}^{A A} & =\frac{k_{h}\left(k_{h}-k_{l}\right)\left[4 t^{2}+k_{l}^{2}(1+\bar{\theta})-4 k_{l} t\right]}{k_{l}\left(4 k_{h}-k_{l}\right)^{2}} \\
\pi_{h}^{A A} & =\frac{\left(k_{h}-k_{l}\right)\left[t^{2}+4 k_{h}^{2}(1+\bar{\theta})-4 k_{h} t\right]}{\left(4 k_{h}-k_{l}\right)^{2}} \\
\pi_{l}^{B B} & =\frac{k_{h}\left(k_{h}-k_{l}\right)\left[4 t^{2}+k_{l}^{2} \bar{\theta}(1+\bar{\theta})-4 k_{l} t \bar{\theta}\right]}{k_{l}\left(4 k_{h}-k_{l}\right)^{2}} \\
\pi_{h}^{B B} & =\frac{\left(k_{h}-k_{l}\right)\left[t^{2}+4 k_{h}^{2} \bar{\theta}(1+\bar{\theta})-4 k_{h} t \bar{\theta}\right]}{\left(4 k_{h}-k_{l}\right)^{2}} .
\end{aligned}
$$

We can simply check that $\pi_{h}^{A B}>\pi_{h}^{B B}, \pi_{l}^{B A}>\pi_{l}^{B B}$ and $\pi_{h}^{B A}>\pi_{h}^{A A}$ for all $\bar{\theta} \geqslant 1$. Comparing $\pi_{l}^{A A}$ with $\pi_{l}^{A B}$ gives:

$$
\pi_{l}^{A A}-\pi_{l}^{A B}=\frac{k_{h}\left(2 k_{h}-k_{l}\right) t^{2}\left[k_{l}+2 k_{h}(\bar{\theta}-1)-3 k_{l} \bar{\theta}\right]}{\bar{\theta}\left(k_{h}-k_{l}\right) k_{l}\left(4 k_{h}-k_{l}\right)^{2}} \gtreqless 0 \text { iff } \bar{\theta} \gtreqless \bar{\theta}_{1},
$$

where $\bar{\theta}_{1}=\frac{\left(2 k_{h}-k_{l}\right)}{\left(2 k_{h}-3 k_{l}\right)}$. 


\section{Appendix A3}

In this Appendix we provide the calculations for the social welfare analysis when regions show different market size. By using the equilibrium prices written in eq. (A1.1)-(A1.8), we get the following values for the indifference taste parameters respectively in locations $(\mathrm{AB}),(\mathrm{BA}),(\mathrm{AA}),(\mathrm{BB})$ :

$(\mathrm{AB})$

$$
\left\{\begin{aligned}
\theta_{0}^{A} & =\frac{k_{l}\left(k_{h}-k_{l}\right)+2 t k_{h}}{k_{k}\left(4 k_{h}-k_{l}\right)} & \theta_{0}^{B} & =\frac{k_{h}-k_{l}+t}{4 k_{h}-k_{l}} \\
\theta_{1}^{A} & =\frac{2 k_{h}^{2}+k_{l}^{2}-k_{h}\left(3 k_{l}+t\right)}{\left(k_{h}-k_{l}\right)\left(4 k_{h}-k_{l}\right)} & \theta_{1}^{B} & =\frac{\left(2 k_{h}-k_{l}\right)\left(k_{h}-k_{l}+t\right)}{\left(k_{h}-k_{l}\right)\left(4 k_{h}-k_{l}\right)}
\end{aligned}\right.
$$

$$
\left\{\begin{aligned}
\theta_{0}^{A} & =\frac{k_{h}-k_{l}+t}{4 k_{h}-k_{l}}\left(k_{h}-k_{l}+t\right) & & \theta_{0}^{B}=\frac{k_{l}\left(k_{h}-k_{l}\right)+2 t k_{h}}{k_{l}\left(4 k_{h}-k_{l}\right)} \\
\theta_{1}^{A} & =\frac{\left(2 k_{h}-k_{l}\right)\left(k_{h}\right.}{\left(k_{h}-k_{l}\right)\left(4 k_{h}-k_{l}\right)} & \theta_{1}^{B} & =\frac{2 k_{h}^{2}+k_{l}^{2}-k_{h}\left(3 k_{l}+t\right)}{\left(k_{h}-k_{l}\right)\left(4 k_{h}-k_{l}\right)}
\end{aligned}\right.
$$

(AA) $\left\{\begin{array}{l}\theta_{0}^{A}=\frac{k_{h}-k_{l}}{4 k_{h}-k_{l}} \\ \theta_{1}^{A}=\frac{2 k_{h}-k_{l}}{4 k_{h}-k_{l}}\end{array}\right.$

$$
\begin{aligned}
\theta_{0}^{B} & =\frac{k_{l}\left(k_{h}-k_{l}\right)+t\left(2 k_{h}+k_{l}\right)}{k_{l}\left(4 k_{h}-k_{l}\right)} \\
\theta_{1}^{B} & =\frac{2 k_{h}-k_{l}+t}{4 k_{h}-k_{l}}
\end{aligned}
$$

$$
\left\{\begin{aligned}
\theta_{0}^{A} & =\frac{k_{l}\left(k_{h}-k_{l}\right)+t\left(2 k_{h}+k_{l}\right)}{k_{l}\left(4 k_{h}-k_{l}\right)} & & \theta_{0}^{B}=\frac{k_{h}-k_{l}}{4 k_{h}-k_{l}} \\
\theta_{1}^{A} & =\frac{2 k_{h}-k_{l}+t}{4 k_{h}-k_{l}} & \theta_{1}^{B} & =\frac{2 k_{h}-k_{l}}{4 k_{h}-k_{l}}
\end{aligned}\right.
$$

In correspondence of the four location choices, social welfare is:

$$
\begin{aligned}
& S W_{A B}=\alpha\left[\int_{\theta_{0}^{A}}^{\theta_{1}^{A}}\left(\theta k_{l}-t\right) \mathrm{d} \theta+\int_{\theta_{1}^{A}}^{1} \theta k_{h} \mathrm{~d} \theta\right]+\left[\int_{\theta_{0}^{B}}^{\theta_{1}^{B}} \theta k_{l} \mathrm{~d} \theta+\int_{\theta_{1}^{B}}^{1}\left(\theta k_{h}-t\right) \mathrm{d} \theta\right], \\
& S W_{B A}=\alpha\left[\int_{\theta_{0}^{A}}^{\theta_{1}^{A}} \theta k_{l} \mathrm{~d} \theta+\int_{\theta_{1}^{A}}^{1}\left(\theta k_{h}-t\right) \mathrm{d} \theta\right]+\left[\int_{\theta_{0}^{B}}^{\theta_{1}^{B}}\left(\theta k_{l}-t\right) \mathrm{d} \theta+\int_{\theta_{1}^{B}}^{1} \theta k_{h} \mathrm{~d} \theta\right], \\
& S W_{A A}=\alpha\left[\int_{\theta_{0}^{A}}^{\theta_{1}^{A}} \theta k_{l} \mathrm{~d} \theta+\int_{\theta_{1}^{A}}^{1} \theta k_{h} \mathrm{~d} \theta\right]+\left[\int_{\theta_{0}^{B}}^{\theta_{1}^{B}}\left(\theta k_{l}-t\right) \mathrm{d} \theta+\int_{\theta_{1}^{B}}^{1}\left(\theta k_{h}-t\right) \mathrm{d} \theta\right], \\
& S W_{B B}=\alpha\left[\int_{\theta_{0}^{A}}^{\theta_{1}^{A}}\left(\theta k_{l}-t\right) \mathrm{d} \theta+\int_{\theta_{1}^{A}}^{1}\left(\theta k_{h}-t\right) \mathrm{d} \theta\right]+\left[\int_{\theta_{0}^{B}}^{\theta_{1}^{B}} \theta k_{l} \mathrm{~d} \theta+\int_{\theta_{1}^{B}}^{1} \theta k_{h} \mathrm{~d} \theta\right] .
\end{aligned}
$$

Since location $A$ has a larger market size than $B$, we conclude that agglomeration in $B$ is always strictly dominated by agglomeration in $A$ from a social point of view. Calculating the social welfare in correspondence of the four location choices, ${ }^{16}$ we get that:

$$
\begin{aligned}
& S W_{A B}>S W_{A A}>S W_{B A}>S W_{B B} \text { iff } 1 \leqslant \alpha<\alpha_{3}, \\
& S W_{A A}>S W_{A B}>S W_{B A}>S W_{B B} \text { iff } \alpha>\alpha_{3},
\end{aligned}
$$

with $\alpha_{3}=\frac{4 k_{l}\left(2 k_{h}^{2}-3 k_{h} k_{l}+k_{l}^{2}\right)-t\left(12 k_{h}^{2}-25 k_{h} k_{l}+8 k_{l}^{2}\right)}{4 k_{l}\left(2 k_{h}^{2}-3 k_{h} k_{l}+k_{l}^{2}\right)-t\left(12 k_{h}^{2}-9 k_{h} k_{l}+2 k_{l}^{2}\right)}$.

\footnotetext{
${ }^{16}$ The computations are available on request.
} 


\section{Appendix A4}

In this Appendix we provide the main calculations for the social welfare analysis when regions show different willingness to pay. By using the equilibrium prices written in eq. (A2.1)-(A2.8), we get the following values for the indifference taste parameters respectively in firms' locations (AB), (BA), (AA), (BB):
$(\mathrm{AB}) \quad\left\{\begin{array}{l}\theta_{0}^{A}=\frac{\bar{\theta} k_{l}\left(k_{h}-k_{l}\right)+2 t k_{h}}{k_{l}\left(4 k_{h}-k_{l}\right)} \\ \theta_{1}^{A}=\frac{\bar{\theta}\left(2 k_{h}^{2}+k_{l}^{2}\right)-k_{h}\left(3 \bar{\theta} k_{l}+t\right)}{\left(k_{h}-k_{l}\right)\left(4 k_{h}-k_{l}\right)}\end{array}\right.$
$\begin{aligned} \theta_{0}^{B} & =\frac{k_{h}-k_{l}+t}{4 k_{h}-k_{l}} \\ \theta_{1}^{B} & =\frac{\left(2 k_{h}-k_{l}\right)\left(k_{h}-k_{l}+t\right)}{\left(k_{h}-k_{l}\right)\left(4 k_{h}-k_{l}\right)}\end{aligned}$
(BA) $\left\{\begin{aligned} \theta_{0}^{A} & =\frac{\bar{\theta}\left(k_{h}-k_{l}\right)+t}{4 k_{h}-k_{l}} \\ \theta_{1}^{A} & =\frac{\left(2 k_{h}-k_{l}\right)\left[\bar{\theta}\left(k_{h}-k_{l}\right)+t\right]}{\left(k_{h}-k_{l}\right)\left(4 k_{h}-k_{l}\right)}\end{aligned}\right.$
$\begin{aligned} \theta_{0}^{B} & =\frac{k_{l}\left(k_{h}-k_{l}\right)+2 t k_{h}}{k_{l}\left(4 k_{h}-k_{l}\right)} \\ \theta_{1}^{B} & =\frac{2 k_{h}^{2}+k_{l}^{2}-k_{h}\left(3 k_{l}+t\right)}{\left(k_{h}-k_{l}\right)\left(4 k_{h}-k_{l}\right)}\end{aligned}$
(AA) $\left\{\begin{aligned} \theta_{0}^{A} & =\frac{\bar{\theta}\left(k_{h}-k_{l}\right)}{4 k_{h}-k_{l}} \\ \theta_{1}^{A} & =\frac{\bar{\theta}\left(2 k_{h}-k_{l}\right)}{4 k_{h}-k_{l}}\end{aligned}\right.$
$\theta_{0}^{B}=\frac{k_{l}\left(k_{h}-k_{l}\right)+t\left(2 k_{h}+k_{l}\right)}{k_{l}\left(4 k_{h}-k_{l}\right)}$
(BB) $\left\{\begin{aligned} \theta_{0}^{A} & =\frac{\bar{\theta} k_{l}\left(k_{h}-k_{l}\right)+t\left(2 k_{h}+k_{l}\right)}{k_{l}\left(4 k_{h}-k_{l}\right)} \\ \theta_{1}^{A} & =\frac{\bar{\theta}\left(2 k_{h}-k_{l}\right)+t}{4 k_{h}-k_{l}}\end{aligned}\right.$
$\theta_{1}^{B}=\frac{2 k_{h}-k_{l}+t}{4 k_{h}-k_{l}}$
$\begin{aligned} \theta_{0}^{B} & =\frac{k_{h}-k_{l}}{4 k_{h}-k_{l}} \\ \theta_{1}^{B} & =\frac{2 k_{h}-k_{l}}{4 k_{h}-k_{l}}\end{aligned}$

In correspondence of the four location choices, social welfare is:

$S W_{A B}=\frac{1}{\bar{\theta}}\left[\int_{\theta_{0}^{A}}^{\theta_{1}^{A}}\left(\theta k_{l}-t\right) \mathrm{d} \theta+\int_{\theta_{1}^{A}}^{\bar{\theta}} \theta k_{h} \mathrm{~d} \theta\right]+\left[\int_{\theta_{0}^{B}}^{\theta_{1}^{B}} \theta k_{l} \mathrm{~d} \theta+\int_{\theta_{1}^{B}}^{1}\left(\theta k_{h}-t\right) \mathrm{d} \theta\right]$,
$S W_{B A}=\frac{1}{\bar{\theta}}\left[\int_{\theta_{0}^{A}}^{\theta_{1}^{A}} \theta k_{l} \mathrm{~d} \theta+\int_{\theta_{1}^{A}}^{\bar{\theta}}\left(\theta k_{h}-t\right) \mathrm{d} \theta\right]+\left[\int_{\theta_{0}^{B}}^{\theta_{1}^{B}}\left(\theta k_{l}-t\right) \mathrm{d} \theta+\int_{\theta_{1}^{B}}^{1} \theta k_{h} \mathrm{~d} \theta\right]$,
$S W_{A A}=\frac{1}{\bar{\theta}}\left[\int_{\theta_{0}^{A}}^{\theta_{1}^{A}} \theta k_{l} \mathrm{~d} \theta+\int_{\theta_{1}^{A}}^{\bar{\theta}} \theta k_{h} \mathrm{~d} \theta\right]+\left[\int_{\theta_{0}^{B}}^{\theta_{1}^{B}}\left(\theta k_{l}-t\right) \mathrm{d} \theta+\int_{\theta_{1}^{B}}^{1}\left(\theta k_{h}-t\right) \mathrm{d} \theta\right]$,
$S W_{B B}=\frac{1}{\bar{\theta}}\left[\int_{\theta_{0}^{A}}^{\theta_{1}^{A}}\left(\theta k_{l}-t\right) \mathrm{d} \theta+\int_{\theta_{1}^{A}}^{\bar{\theta}}\left(\theta k_{h}-t\right) \mathrm{d} \theta\right]+\left[\int_{\theta_{0}^{B}}^{\theta_{1}^{B}} \theta k_{l} \mathrm{~d} \theta+\int_{\theta_{1}^{B}}^{1} \theta k_{h} \mathrm{~d} \theta\right]$.

Substituting the equilibrium values for the indifference taste parameters,${ }^{17}$ we get that the highest social welfare is realized in (BA), in fact:

$$
\begin{aligned}
& S W_{B A}>S W_{A B}>S W_{A A}>S W_{B B} \text { iff } 1 \leqslant \bar{\theta}<\bar{\theta}_{2}, \\
& S W_{B A}>S W_{A A}>S W_{A B}>S W_{B B} \text { iff } \bar{\theta}>\bar{\theta}_{2},
\end{aligned}
$$

where $\bar{\theta}_{2}=\frac{12 k_{h}^{2}-9 k_{h} k_{l}+2 k_{l}^{2}}{12 k_{h}^{2}-25 k_{h} k_{l}+8 k_{l}^{2}}$.

\footnotetext{
${ }^{17}$ The computations are available on request.
} 